\title{
Mechanochemical Treatment of Historical Tungsten Tailings: Leaching While Grinding for Tungsten Extraction Using NaOH
}

\author{
Jane Mulenshi * ${ }^{\mathbb{D}}$, Saeed Chehreh Chelgani $(\mathbb{D})$ and Jan Rosenkranz
}

Citation: Mulenshi, J.; Chelgani, S.C.; Rosenkranz, J. Mechanochemical Treatment of Historical Tungsten Tailings: Leaching While Grinding for Tungsten Extraction Using $\mathrm{NaOH}$. Sustainability 2021, 13, 3258. https:// doi.org/10.3390/su13063258

Academic Editors: Ismael Matino, Valentina Colla and Glen Corder

Received: 29 January 2021

Accepted: 12 March 2021

Published: 16 March 2021

Publisher's Note: MDPI stays neutral with regard to jurisdictional claims in published maps and institutional affiliations.

Copyright: (c) 2021 by the authors. Licensee MDPI, Basel, Switzerland. This article is an open access article distributed under the terms and conditions of the Creative Commons Attribution (CC BY) license (https:// creativecommons.org/licenses/by/ $4.0 /)$.
Division of Minerals and Metallurgical Engineering, Luleå University of Technology, SE-971 87 Luleå, Sweden; saeed.chelgani@ltu.se (S.C.C.); jan.rosenkranz@ltu.se (J.R.)

* Correspondence: jane.mulenshi@ltu.se; Tel.: +46-920-493673

\begin{abstract}
Innovative tungsten (W) extraction techniques are continually being sought because of challenges of low leaching efficiencies, despite using advanced processing units such as autoclaves operating high temperatures and pressures. Compared to conventional leaching, mechanochemical treatment improves the efficiency of leaching. Therefore, in this study, an innovative mechanochemical treatment method, referred to as leaching while grinding (LWG), was employed as a reprocessing option to optimize W recovery from historical tungsten tailings. Experiments were run using the regular two-level factorial design to screen through the four factors of stirrer speed, liquid/solid ratio, temperature, and digestion time to assess their criticality and effects in the LWG process. The stirrer speed and the liquid/solid ratio were the most critical factors in the optimization of $\mathrm{W}$ recovery. The maximum $\mathrm{W}$ recovery $(91.2 \%)$ was attained at the highest stirrer speed (410 rpm), low liquid/solid ratio $(0.8)$, long digestion time $(6 \mathrm{~h})$, and low leaching temperature $\left(60^{\circ} \mathrm{C}\right)$. The attained low leaching temperature $\left(60^{\circ} \mathrm{C}\right)$ was due to the mechanical activation of scheelite resulting from the simultaneous grinding and leaching. For such low-grade $\mathrm{W}$ material, liquid/solid ratio optimizing is critical for maintaining the digestion mixture fluidity, and for environmental and economic sustainability regarding the sodium hydroxide $(\mathrm{NaOH})$ consumption, which was low.
\end{abstract}

Keywords: mechanical activation; scheelite; tailings; reprocessing; leaching; grinding

\section{Introduction}

Tungsten (W) is a critical raw material for the European Union [1], with scheelite $\left(\mathrm{CaWO}_{4}\right)$ and wolframite $\left((\mathrm{Fe}, \mathrm{Mn}) \mathrm{WO}_{4}\right)$ being the most important tungsten ore minerals $[2,3]$. Over the years, different hydrometallurgical techniques have been used for $\mathrm{W}$ extraction from these ores, mostly from high-grade $W$ concentrates, and synthetic concentrates (scraps) [2]. Different leaching reagents, being either alkaline or acidic or a combination of the two, applied at different stages of the leaching process and reactors have been considered to enhance $W$ extraction efficiency [4-6].

It was documented that mechanochemical treatment can improve the efficiency of leaching $[7,8]$. In the leaching while grinding (LWG) process, the reaction ability of the mineral to be leached is increased (mechanical activation) by grinding using high-energy mills, and in the presence of a leaching reagent, a mechanochemical reaction occurs. The solid mineral particles' increased reactivity is due to increased internal and surface energy, increased surface area, and decreased coherence energy [8]. The mechanical activation in the high-energy mills is achieved by impact (stroke or collision), attrition (shear), and compression. In the LWG process, several factors influence the grinding process and the leaching process; for grinding, the factors include the filling extent of the milling chamber, ball-to-powder ratio (BPR), and grinding speed and time, while for leaching, the factors include temperature, reagent concentration, stirring speed, and leaching time [8-12]. However, the mechanical activation in the extractive metallurgy from primary or secondary resources has not been considered widely, and few applications are reported for the gold 
extraction [13-15]. Gold amalgamation (mill leaching) is an efficient practice in small mines [16]. For reducing the media and liner corrosion, LWG is mostly performed in alkaline conditions.

Zhao et al. [10] showed the advantages of hydroxide leaching of scheelite over carbonate processing usually done in autoclaves to include lower leaching temperature (150 to $170{ }^{\circ} \mathrm{C}$ ), and that a higher leaching solution concentration is beneficial for the decomposition of $\mathrm{W}$ ores, as sodium tungstate $\left(\mathrm{Na}_{2} \mathrm{WO}_{4}\right)$ crystallizes earlier than the sodium hydroxide $(\mathrm{NaOH})$. In more recent studies, the alkaline leachability of scheelite has been enhanced by converting it to $\mathrm{MgWO}_{4}$ through roasting with anhydrous $\mathrm{MgCl}_{2}$ [17]. The large volume of leachant required in alkaline leaching of scheelite has been cited as one of the reasons for exploring acid leaching using hydrochloric acid or a combination of sulphuric acid and phosphoric acid, with mechanical activation in some cases [18-20]. In this study, however, instead of using complex leaching reagents to deal with surface layers on scheelite particles and increase the leaching efficiency, LWG was used. In this method, scheelite was mechanically activated and leached simultaneously in one reactor instead of conducting these steps sequentially in different reactors at varying operating conditions of temperature and pressure $[7,8]$. The mechanical activation of scheelite improves the leaching kinetics as its decomposition temperature is reduced, and the surface area is increased with reducing particle size resulting from grinding $[7,8]$.

Therefore, in the current study, a concentrated $\mathrm{NaOH}$ solution was used to digest scheelite (Equation (1)) in historical tungsten tailings, which is a low-grade W mining waste material, unlike the $W$ ores or scheelite concentrates used in other studies $[4,5,10,21,22]$.

$$
\mathrm{CaWO}_{4(\mathrm{~s})}+2 \mathrm{NaOH}_{(\mathrm{aq})} \leftrightarrow \mathrm{Ca}(\mathrm{OH})_{2(\mathrm{~s})}+\mathrm{Na}_{2} \mathrm{WO}_{4(\mathrm{aq})}
$$

The tailings used in this study were also much coarser $(>75 \mu \mathrm{m})$ than the scheelite concentrates used in other scheelite leaching studies; hence, when selecting factors to optimize the LWG process, factors that improve both scheelite leaching kinetics and grinding in a stirred media mill were considered [12,23]. The effects of leaching temperature, $\mathrm{NaOH}$ solution concentration, mineral particle size, liquid/solid ratio, and stirring speed are significant to both the digestion of scheelite by $\mathrm{NaOH}$ and the leaching rate $[5,10,24]$. These effects have been investigated in various studies using different statistical and graphical techniques [23,25], and in this study, this approach was also taken.

Indicative tests to compare conventional leaching to LWG at different temperatures were conducted on scheelite concentrate before the LWG test in this study. W recovery was 4.8 times higher at $38^{\circ} \mathrm{C}, 1.8$ times higher at $60^{\circ} \mathrm{C}$, and 0.5 times lower at $80^{\circ} \mathrm{C}$ after $6 \mathrm{~h}$ of leaching, meaning that the grinding improved the leaching kinetics for the lower temperatures, but it had an adverse effect at a higher leaching temperature. However, despite having more improved leaching kinetics at $38^{\circ} \mathrm{C}, \mathrm{W}$ recovery after $6 \mathrm{~h}$ of leaching was too low $(<20 \%)$; thus, the higher temperatures needed to be considered for further tests in this study. This means that grinding had a higher influence on scheelite leaching than temperature. When scheelite is mechanically activated by grinding, its reactivity increases, causing it to be leached faster, thus forming soluble $\mathrm{Na}_{2} \mathrm{WO}_{4}$ rapidly, and in a short time, the solution becomes saturated leading to the precipitation of $\mathrm{Na}_{2} \mathrm{WO}_{4}$ until all the scheelite has reacted [26].

Therefore, having characterized the historical tungsten tailings from the Smaltjärnen tailings storage facility (TSF) in Yxsjöberg, Sweden, and considering the reprocessing options including magnetic separation, gravity separation, and froth flotation $[27,28]$, the LWG process employed in this current study was a more innovative method of reprocessing these historical tailings. Ideally, with the simultaneous grinding of the tailings and leaching of scheelite, the comminution of the tailings particles would be further improved, scheelite mineral grains would be more liberated with increased surface area, and with the refreshing of surfaces, scheelite leaching would be enhanced.

The regular two-level factorial design for running experiments was picked to screen through the four factors of stirrer speed, liquid/solid ratio, temperature, and digestion 
time to assess their criticality and effects in the LWG process. The aim was to optimize the LWG process for $\mathrm{W}$ recovery from historical tungsten tailings.

\section{Materials and Methods}

\subsection{Feed Properties}

The feed material used was historical tungsten tailings samples collected from the Smaltjärnen TSF in Yxsjöberg, Sweden, estimated to have about 2.2 million tons of tailings, and covering an area of 26 hectares [27]. In this study, $26 \mathrm{~g}$ of the tailings sample was used for each experimental run based on the ball-to-powder ratio (BPR) of 50 [12], with the particle size distribution of -600 to $+75 \mu \mathrm{m}$ (Figure 1), and an average density of $3.35 \mathrm{~g} / \mathrm{cm}^{3}$ determined using a He pycnometer. Particle size distribution was conducted on three different tailings samples using dry sieving in five size fractions $(>600 \mu \mathrm{m},-600$ to $+300 \mu \mathrm{m},-300$ to $+150 \mu \mathrm{m},-150$ to $+75 \mu \mathrm{m}$, and $<75 \mu \mathrm{m}$ ). Chemical analysis was conducted using the inductively coupled plasma-sector field mass spectrometry (ICPSFMS) method, while the bulk mineralogical phases in which the high concentration elements were hosted were determined using X-ray diffraction (XRD) (Figure 2). In order to find the mineral phases of interest in the tailings using XRD, prior knowledge of the mineral composition of the primary ore from which these tailings were generated was essential [29]. This is because, for minerals like scheelite with very low concentration in the tailings, finding them in the XRD candidate list was only possible by using restrictions when executing the "search and match" function in the HighScore Plus software. The element of interest in this study, $\mathrm{W}$, was among the minor elements (Table 1), while the feed material's major elemental composition was $\mathrm{CaO}, \mathrm{Fe}_{2} \mathrm{O}_{3}$, and $\mathrm{SiO}_{2}$ (Table 2).

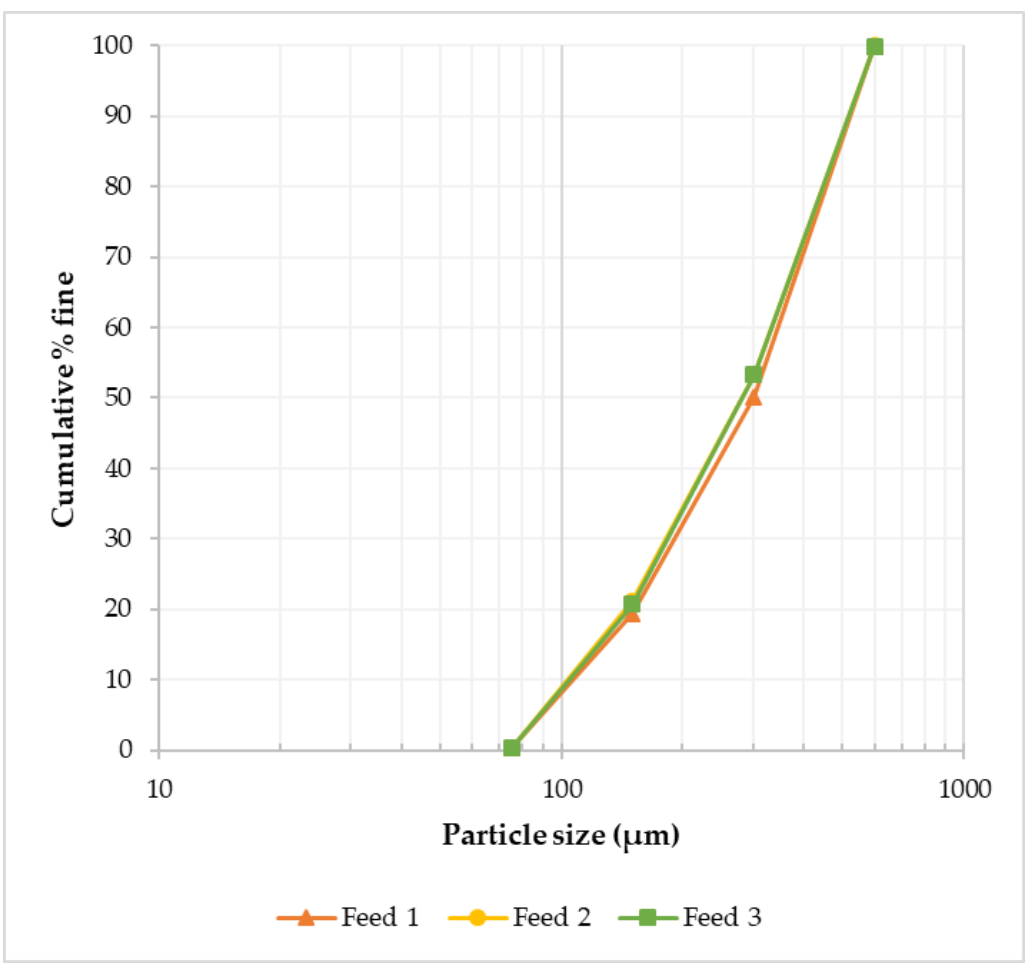

Figure 1. Feed material (historical tungsten tailings) particle size distribution in three samples, showing similar distributions. 


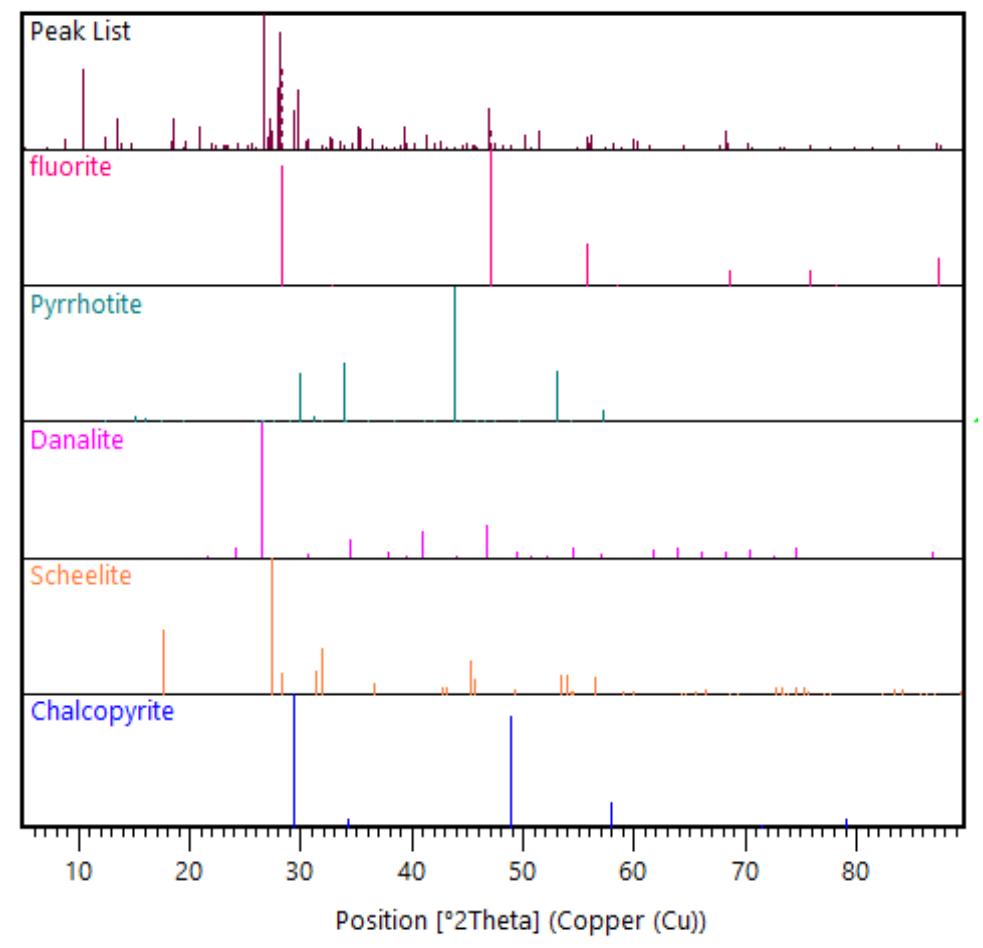

Figure 2. X-ray diffraction (XRD) pattern view of selected mineral phase patterns in the feed material.

Table 1. Feed material minor elements of interest and their main host minerals.

\begin{tabular}{ccc}
\hline Element & Average Concentration $\mathbf{( m g / k g )}$ & Main Mineral \\
\hline $\mathrm{Be}$ & 271 & Danalite \\
$\mathrm{Bi}$ & 363 & Bismuthinite \\
$\mathrm{Cu}$ & 988 & Chalcopyrite \\
$\mathrm{S}$ & 14,475 & Pyrite, Pyrrhotite \\
$\mathrm{Sn}$ & 564 & Cassiterite \\
$\mathrm{W}$ & 1125 & Scheelite \\
$\mathrm{Zn}$ & 263 & Sphalerite \\
\hline
\end{tabular}

Table 2. Feed material major elements and loss on ignition (LOI) content.

\begin{tabular}{cc}
\hline Element & Average Concentration (\%) \\
\hline $\mathrm{SiO}_{2}$ & 41.7 \\
$\mathrm{Al}_{2} \mathrm{O}_{3}$ & 5.5 \\
$\mathrm{CaO}$ & 16.7 \\
$\mathrm{Fe}_{2} \mathrm{O}_{3}$ & 21.6 \\
$\mathrm{MgO}$ & 1.2 \\
$\mathrm{MnO}$ & 1.4 \\
$\mathrm{Na}$ & 1.2 \\
$\mathrm{LOI}$ & 1.6 \\
\hline
\end{tabular}

\subsection{Leaching Procedure}

Leaching experiments were conducted in an insulated water-heated attritor mill with different parameters (Figure 3 and Table 3). Sodium hydroxide $(\mathrm{NaOH})$ at $10 \mathrm{M}$, with an average $\mathrm{pH}$ of 13.56, was used to digest the tailings samples [24]. The liquid/solid ratio factor, temperature, digestion time, and stirrer speed were other factors investigated in this study to assess their effect on the $W$ recovery from historical tailings in the LWG process. For the leaching procedure, experiments were designed using the Design-Expert ${ }^{\circledR}$ software (12.0.12.0, Stat-Ease, Minneapolis, United States, 2020). The regular two-level factorial 
design was picked because of its effectiveness in "screening through many factors to find the critical few", and the two-level full factorial was employed as it "permits estimation of all main effects and all interaction effects" [30].
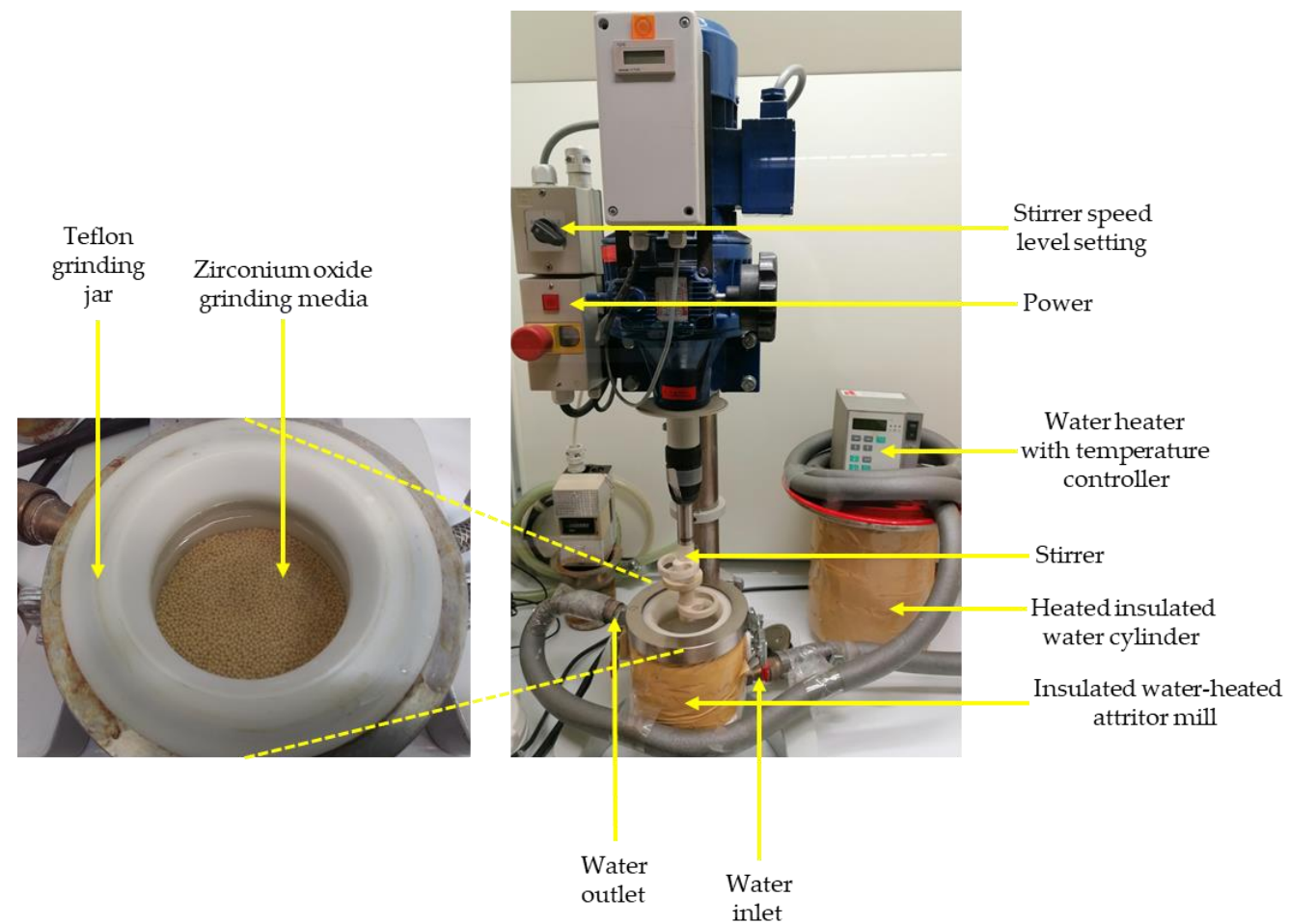

Figure 3. Leaching while grinding experimental setup.

Table 3. Attritor mill and media parameters.

\begin{tabular}{cccc}
\hline \multicolumn{1}{c}{ Mill } & \multicolumn{2}{c}{ Media } \\
\hline Volume $(\mathrm{mL})$ & 500 & Density $\left(\mathrm{g} / \mathrm{cm}^{3}\right)$ & 5.63 \\
\hline Stirrer speed $(\mathrm{rpm})$ & 205 & Mass $(\mathrm{g})$ & 1285 \\
\hline Ball filling volume $(\mathrm{mL})$ & 410 & Volume $\left(\mathrm{cm}^{3}\right)$ & 228 \\
\hline & 350 & Ball size $(\mathrm{mm})$ & -2.38 to +1.68 \\
\hline
\end{tabular}

For the factor level type, the stirrer speed was defined as "categoric" because the attritor mill could only be run at two set speeds; hence, a range between the low and high levels would not be available, as was the case for the other three factors defined as "numeric" (Table 4). The digested tailings sample from each experimental run was then washed for $10 \mathrm{~min}$ in $300 \mathrm{~mL}$ of $\mathrm{NaOH}$ leaching solution at $1 \mathrm{M}$ concentration, which gives a higher $\mathrm{Na}_{2} \mathrm{WO}_{4}$ solubility [22]. The leachate was analyzed for $\mathrm{W}$, including other metals and elements, using the ICP-SFMS method, and the $\mathrm{W}$ recovery was calculated. 
Table 4. Experiment design factors and settings.

\begin{tabular}{|c|c|c|c|c|c|c|c|c|c|}
\hline Factor & Name & Units & Type & Minimum & Maximum & $\begin{array}{l}\text { Coded } \\
\text { Low }\end{array}$ & $\begin{array}{c}\text { Coded } \\
\text { High }\end{array}$ & Mean & Std. Dev. \\
\hline A & Temperature & ${ }^{\circ} \mathrm{C}$ & Numeric & -1.0000 & 1.0000 & $\begin{array}{l}-1 \leftrightarrow \\
-1.00\end{array}$ & $+1 \leftrightarrow 1.00$ & 0.0000 & 1.03 \\
\hline B & $\begin{array}{l}\text { Digestion } \\
\text { time }\end{array}$ & hours & Numeric & -1.0000 & 1.0000 & $\begin{array}{l}-1 \leftrightarrow \\
-1.00\end{array}$ & $+1 \leftrightarrow 1.00$ & 0.0000 & 1.03 \\
\hline $\mathrm{C}$ & Liquid/solid & ratio & Numeric & -1.0000 & 1.0000 & $\begin{array}{l}-1 \leftrightarrow \\
-1.00\end{array}$ & $+1 \leftrightarrow 1.00$ & 0.0000 & 1.03 \\
\hline $\mathrm{D}$ & $\begin{array}{l}\text { Stirrer } \\
\text { speed }\end{array}$ & $\mathrm{rpm}$ & Categoric & 205 & 410 & & & Levels: & 2.00 \\
\hline
\end{tabular}

The experimental design involved 16 completely randomized runs (Table 5), with W recovery as the response. The real values for temperature, digestion time, and liquid/solid ratio coded low (-1) were $60^{\circ} \mathrm{C}, 4 \mathrm{~h}$, and 0.8 , while coded high (+1) they were $98^{\circ} \mathrm{C}, 6 \mathrm{~h}$, and 1.0, respectively. For the design post-analysis, the best numerical optimization solution was picked to run two replicate verification tests; two tests were conducted using the tailings material. For the other two tests, scheelite concentrate with $66.2 \% \mathrm{WO}_{3}$ grade was used so that a comparison could be made to the indicative LWG tests that were conducted before the LWG tests in this study. The notable differences between the indicative LWG tests and the LWG tests in this study were in the amount of concentrated $\mathrm{NaOH}$ solution used and the two leaching stages; digestion with the concentrated (10 M) $\mathrm{NaOH}$ solution, washing with the diluted $(1 \mathrm{M}) \mathrm{NaOH}$ solution, and sampling of the leachate could not be done during the leaching process [24]. An additional replicate test using the tailings material, but leaching without grinding (LWTG), was conducted as a control experiment so that the effect of mechanical activation on $\mathrm{W}$ recovery could be compared.

Table 5. Experiment design layout.

\begin{tabular}{|c|c|c|c|c|c|}
\hline & & Factor 1 & Factor 2 & Factor 3 & Factor 4 \\
\hline Std & Run & A: Temperature & B: Digestion Time & C: Liquid/Solid & D: Stirrer Speed \\
\hline & & ${ }^{\circ} \mathrm{C}$ & Hours & Ratio & rpm \\
\hline 16 & 1 & 1 & 1 & 1 & 410 \\
\hline 7 & 2 & -1 & 1 & 1 & 205 \\
\hline 1 & 3 & -1 & -1 & -1 & 205 \\
\hline 8 & 4 & 1 & 1 & 1 & 205 \\
\hline 14 & 5 & 1 & -1 & 1 & 410 \\
\hline 9 & 6 & -1 & -1 & -1 & 410 \\
\hline 2 & 7 & 1 & -1 & -1 & 205 \\
\hline 11 & 8 & -1 & 1 & -1 & 410 \\
\hline 6 & 9 & 1 & -1 & 1 & 205 \\
\hline 15 & 10 & -1 & 1 & 1 & 410 \\
\hline 4 & 11 & 1 & 1 & -1 & 205 \\
\hline 10 & 12 & 1 & -1 & -1 & 410 \\
\hline 5 & 13 & -1 & -1 & 1 & 205 \\
\hline 12 & 14 & 1 & 1 & -1 & 410 \\
\hline 13 & 15 & -1 & -1 & 1 & 410 \\
\hline 3 & 16 & -1 & 1 & -1 & 205 \\
\hline
\end{tabular}

\section{Results and Discussion}

\subsection{Factorial Design Analysis}

\subsubsection{Significant and Insignificant Factor Effects}

The concentration of $\mathrm{W}$ in the leachate was used to calculate the $\mathrm{W}$ recovery (main design response) from the tungsten tailings (Figure 4). The experiment design was evaluated on the reduced two-factor interactions (2FI); the four main factors $(\mathrm{A}, \mathrm{B}, \mathrm{C}$, and $\mathrm{D})$ 
and three $2 \mathrm{FI}(\mathrm{AB}, \mathrm{AD}$, and $\mathrm{CD})$ terms were identified as significant factors, which were separated from the insignificant effects using the half-normal plot method (Figure 5). It was observed that the stirrer speed (D), temperature (A), and digestion time (B) had positive effects, meaning an increase in these main factors would increase the $\mathrm{W}$ recovery. The stirrer speed had the largest contribution of $58.5 \%$ because it relates to the particle size reduction, increases the surface area, and enhances the reactivity of scheelite $[10,23]$. It also enhances mass transfer in the highly viscous $\mathrm{NaOH}$ digestion solution and continuously removes the $\mathrm{Ca}(\mathrm{OH})_{2}$ solid product layers that form on scheelite mineral particles as the accelerated rate-determining chemical reaction (Equation (1)) proceeds [5,13,21,22].

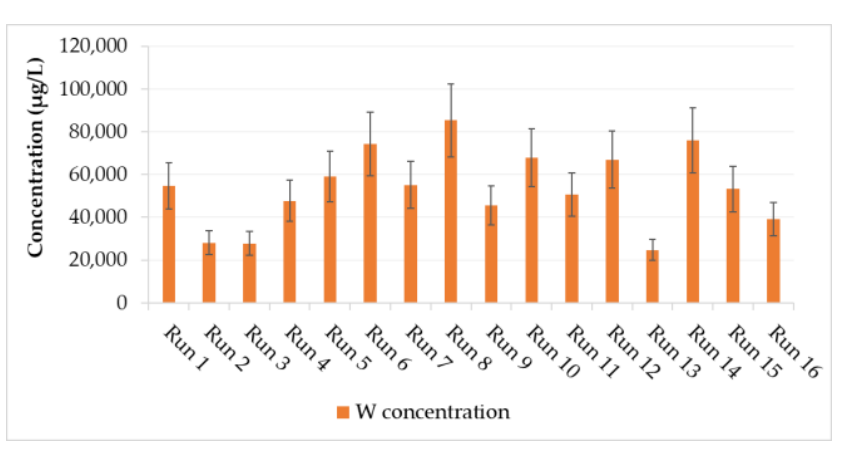

(a)

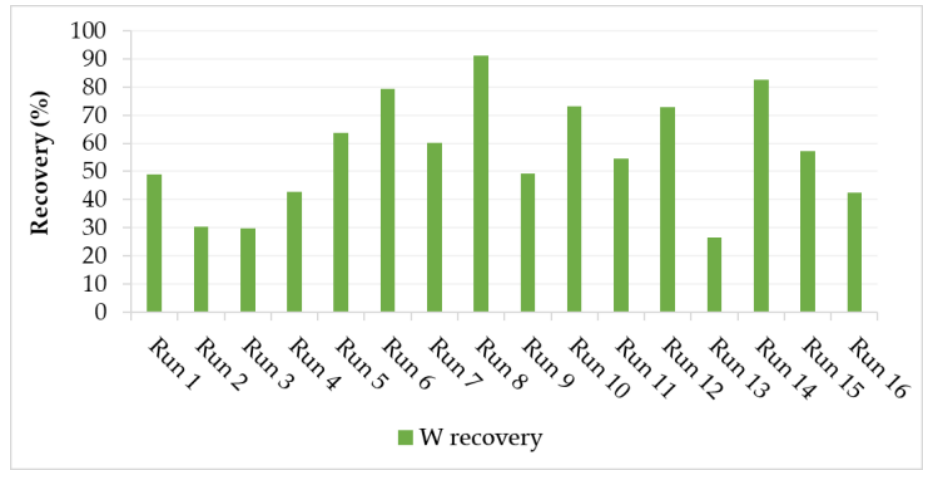

(b)

Figure 4. Design responses from the 16 different experimental runs: (a) tungsten (W) concentration in leachate and (b) W recovery from historical tungsten tailings.

\section{W recovery \\ Shapiro-Wilk test \\ W-value $=0.978$ \\ $\mathrm{p}$-value $=0.953$ \\ A: Temperature \\ B: Digestion time \\ C: Liquid/solid \\ D: Stirrer speed}

Positive Effects

Negative Effects

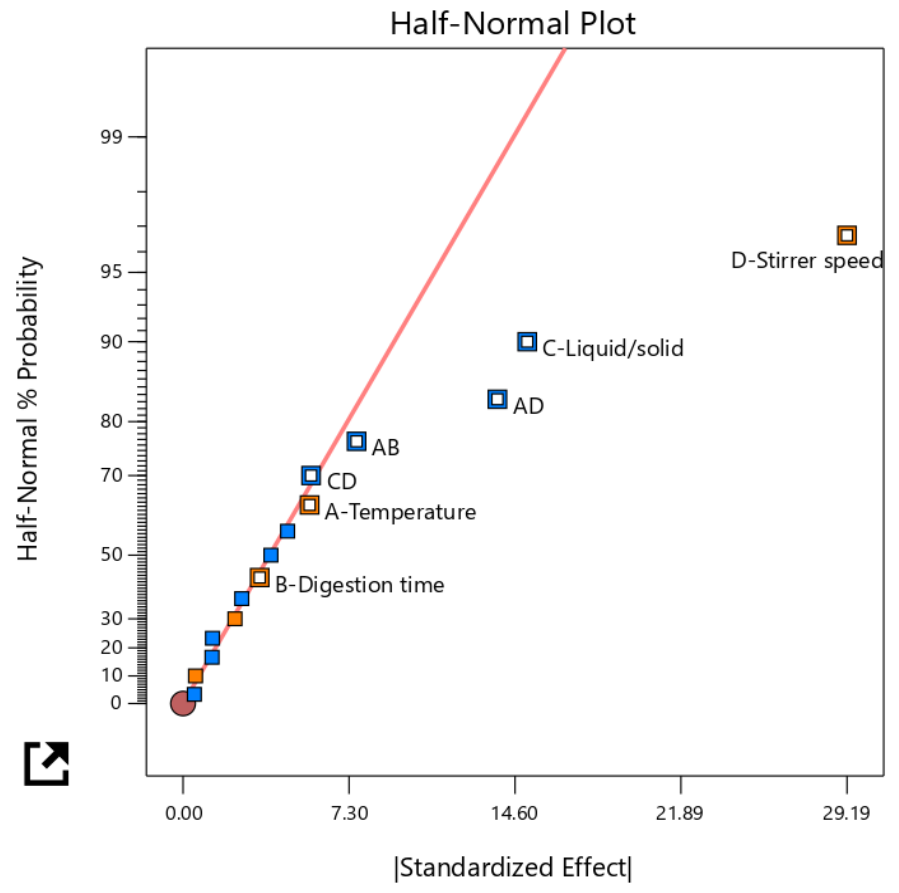

Figure 5. The half-normal plot showing the selected significant factor effects.

Despite temperature and digestion time individually having a positive effect on $\mathrm{W}$ recovery, their interactions $(\mathrm{AB})$ showed a negative effect, and this contribution was larger than that of the individual factors. Similarly, the AD factor interaction had a negative effect with an even larger contribution (13.1\%) than the $A B$ factor interaction; hence, it was important to observe these factor interactions for the optimizing model. With the mechanical activation of scheelite brought about by the grinding occurring simultaneously 
with the leaching in the LWG process in this study, one expected and desired advantage was reduced leaching temperature, which would then make the factor interactions $A B$ and $\mathrm{AD}$ have a positive effect on $\mathrm{W}$ recovery. Another advantage of the mechanical activation of scheelite is the shorter reaction time due to the increased rate of the forward reaction; however, if the digestion time goes beyond this reaction time, $\mathrm{Na}_{2} \mathrm{WO}_{4}$ saturation may occur, and since its solubility is low in the $10 \mathrm{M} \mathrm{NaOH}$ digestion solution, crystallization would also occur $[5,7,22]$. Therefore, having a high temperature, which also increases the leaching rate, and high digestion time results in the negative effect of the $\mathrm{AB}$ factor interaction on $\mathrm{W}$ recovery to the leachate. The recovery of $\mathrm{W}$ would be low because $\mathrm{W}$ would remain in the solute as solid $\mathrm{Na}_{2} \mathrm{WO}_{4}$, especially if the $\mathrm{NaOH}$ dilution in the subsequent washing stage was insufficient for complete dissolution $[2,24,26]$. The digestion time encompassed time for both grinding the tailings particles and the $\mathrm{NaOH}$ digestion of scheelite; hence, a key factor in the mechanical activation of scheelite mineral grains similar to the stirrer speed, but with a very minimal effect and contribution to $\mathrm{W}$ recovery. Since the feed material used in this study was coarse with a very low-grade $W$ material, the grinding also enhanced the liberation of scheelite mineral grains in the tailings particles.

The liquid/solid ratio (C) factor had the second highest effect and contribution to the W recovery, but unlike the other three main factors, this factor had a negative effect on $\mathrm{W}$ recovery. This factor is especially critical for leaching scheelite from very low-grade material such as tailings, because sufficient fluidity of the digestion mixture should be attained such that, even after digesting for a while at a given temperature, the mixture does not solidify. For such low-grade $\mathrm{W}$ material, sufficient fluidity is not attainable using the $\mathrm{NaOH}$ stoichiometric ratio; hence, the $\mathrm{NaOH}$ is in excess, and the $\mathrm{Na}_{2} \mathrm{WO}_{4}$ crystallizes because of its limited solubility in such a highly concentrated $\mathrm{NaOH}$ solution [5]. Therefore, the $\mathrm{CD}$ factor interaction has an equally negative effect unless an optimal liquid/solid ratio is employed.

\subsubsection{Analysis of Variance (ANOVA)}

Based on the above understanding of the selected effects, the model tested significant for the selected seven model terms using ANOVA, and the predictive model in coded terms was as follows:

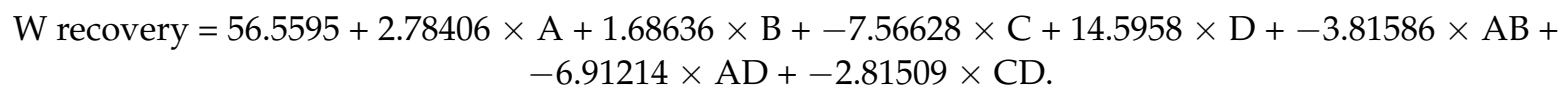

The factor coefficients revealed the relative significance of the factors, with the stirrer speed (D) showing the highest impact on W recovery followed by the liquid/solid ratio (C), as was also observed in the analysis of the effects. The model showed a good fit, as the $\mathrm{R}^{2}$ adjusted and predicted values were in good agreement, with the difference less than 0.2 as recommended, and the model $\mathrm{R}^{2}$ value being 0.964 ; hence, the model was expected to provide good predictions for $\mathrm{W}$ recovery from historical tungsten tailings using the LWG process [31].

\subsubsection{Optimization}

An optimization criterion was determined for each factor and response, with the most important goal being that of maximizing the response $\mathrm{W}$ recovery (Table 6). 
Table 6. Numerical goal optimization criteria.

\begin{tabular}{|c|c|c|c|c|c|c|}
\hline Name & Goal & Lower Limit & Upper Limit & Lower Weight & Upper Weight & Importance \\
\hline A: Temperature & is in range & -1 & 1 & 1 & 1 & 3 \\
\hline B: Digestion time & is in range & -1 & 1 & 1 & 1 & 3 \\
\hline C: Liquid/solid & is in range & -1 & 1 & 1 & 1 & 3 \\
\hline D: Stirrer speed & is in range & 205 & 410 & 1 & 1 & 3 \\
\hline W recovery & maximize & 26.611 & 91.182 & 10 & 1 & 5 \\
\hline
\end{tabular}

Solutions were given for the two combinations of categoric factor levels (205 and $410 \mathrm{rpm}$ ) of the stirrer speed, and the best solutions for each categoric factor level were considered by assessing the 3D response surfaces (Figure 6). It was observed that maximum $\mathrm{W}$ recovery at $91.2 \%$ was best achieved at the highest stirrer speed $(410 \mathrm{rpm})$, a low liquid/solid ratio (0.8), long digestion time $(6 \mathrm{~h})$, and a low leaching temperature at $60{ }^{\circ} \mathrm{C}$ (Figure 6a). This desired outcome confirmed the earlier analysis of the effect of the factors on $\mathrm{W}$ recovery, which found that the mechanical activation of scheelite in the LWG process led to having a lower leaching temperature, with the leaching process conducted in a simpler and less expensive reactor compared to using pressurized reactors such as autoclaves and higher leaching temperatures above $100^{\circ} \mathrm{C}[4,5,7,21,22,24]$. With the low leaching temperature, the $\mathrm{AB}$ and $\mathrm{AD}$ factor interactions did not negatively affect the response (low $\mathrm{W}$ recovery), as the positive effects of the main factors $\mathrm{B}$ and $\mathrm{D}$ dominated. Concerning the leaching process selectivity, other elements of high concentration in the leachate other than $\mathrm{W}$ included $\mathrm{Si}, \mathrm{S}, \mathrm{Pb}, \mathrm{Na}, \mathrm{K}, \mathrm{Fe}, \mathrm{Ca}$, and $\mathrm{Al}$, which would need to be removed in several purification steps before the solvent extraction and the conversion of the purified $\mathrm{Na}_{2} \mathrm{WO}_{4}$ solution to ammonium paratungstate (APT) crystals [2].

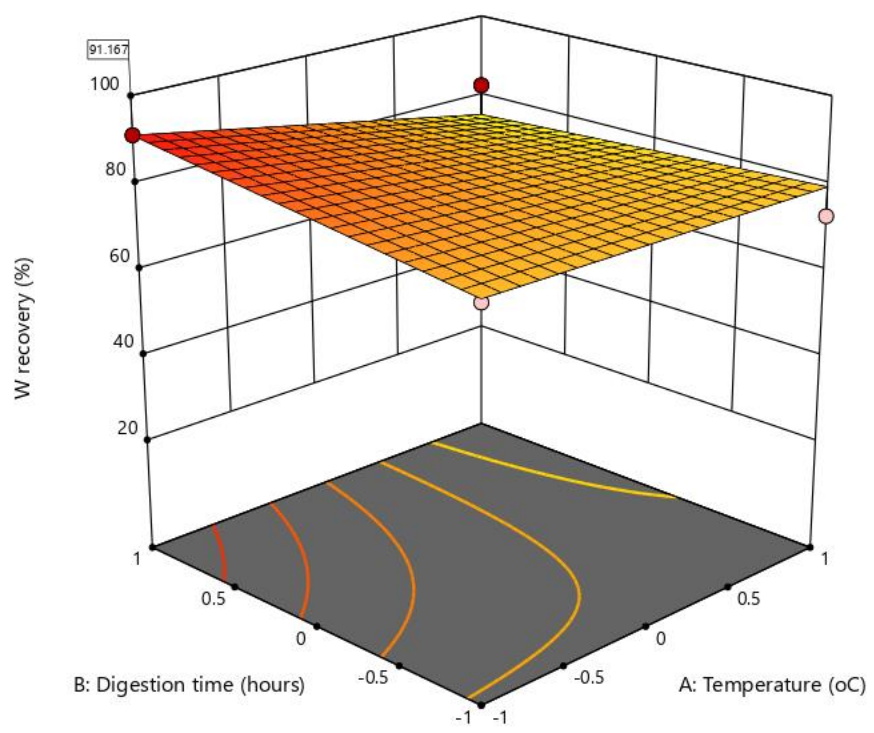

(a)

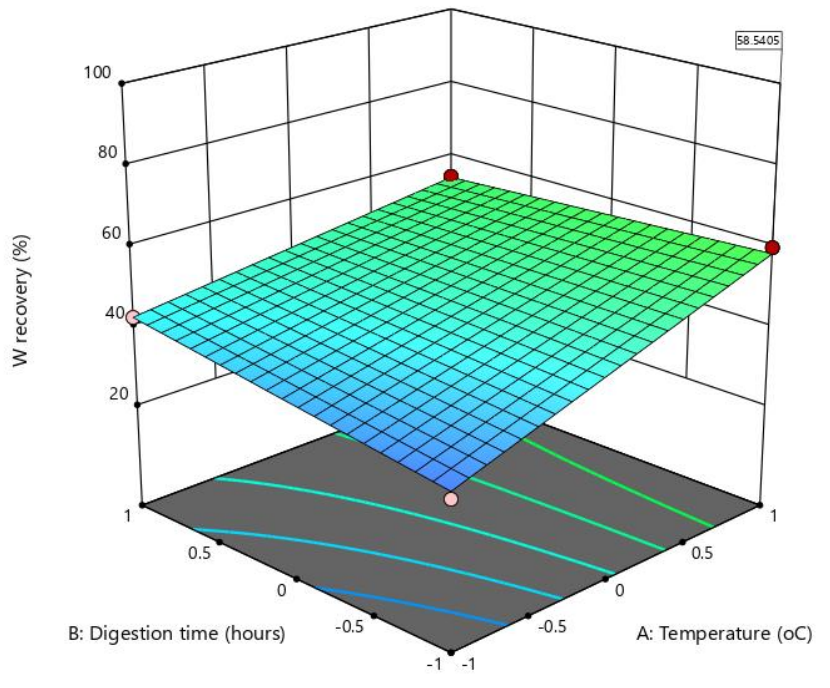

(b)

Figure 6. The 3D response surfaces for the best optimization solution to maximize $\mathrm{W}$ recovery from historical tungsten tailings using the leaching while grinding (LWG) process: (a) liquid/solid ratio $(C)=-1$, stirrer speed $(\mathrm{D})=410 \mathrm{rpm}$, and (b) $C=-1, \mathrm{D}=205 \mathrm{rpm}$.

The negative effects of the $\mathrm{AB}$ and $\mathrm{AD}$ factor interactions were evident in the solution (Figure $6 \mathrm{~b}$ ) that had the lowest stirrer speed (205 rpm), a low liquid/solid ratio (0.8), shorter digestion time $(4 \mathrm{~h})$, and a high leaching temperature $\left(98^{\circ} \mathrm{C}\right)$. Reducing both the stirrer speed and the digestion time to have a high leaching temperature had a more negative effect on $\mathrm{W}$ recovery because the mechanical activation of scheelite was reduced. With the 
coarser tailings used in this study, particle size reduction, which is essential for increased scheelite reactivity $[10,23]$, is less enhanced.

If the energy conservation factor was to be considered, other solutions on the 3D response surface in Figure 6a with a digestion time of less than $6 \mathrm{~h}$ may be compared, though the $\mathrm{W}$ recovery would be lower than $91.2 \%$. Other factors that could also be considered for maximizing $\mathrm{W}$ recovery in this LWG process are the dilution of $\mathrm{NaOH}$ solution in the washing stage, as too much dilution favors the reverse reaction and the duration of washing [24]. Therefore, the solute characterization using XRD to determine in which phases the unleached $\mathrm{W}$ is found would be essential. If $\mathrm{W}$ is found in the $\mathrm{Na}_{2} \mathrm{WO}_{4}$ phase, then the dissolution issue has to be investigated. If $\mathrm{W}$ is found in the $\mathrm{CaWO}_{4}$ phase, then either the scheelite digestion did not occur because of unliberated scheelite grains in the coarse tailings particles, or the reverse reaction could have occurred during the washing stage because of the over-dilution of $\mathrm{NaOH}$.

\subsection{Design Post-Analysis}

The best numerical optimization recommended solution (highest stirrer speed (410 rpm), low liquid/solid ratio $(0.8)$, long digestion time $(6 \mathrm{~h})$, and low leaching temperature at $60^{\circ} \mathrm{C}$ ) was used to conduct verification tests. The obtained mean W recovery for LWG using tailings was within the $95 \%$ prediction interval of the model (79.4\% to $102.9 \%)$ taking into consideration the $20 \%$ error in the $\mathrm{W}$ concentration in the leachate (Figure 7 ); hence, the model was confirmed. For LWG using the scheelite concentrate, the $\mathrm{NaOH}$ was not in excess as the 0.8 liquid/solid ratio was equivalent to the $1: 2 \mathrm{CaWO}_{4} / \mathrm{NaOH}$ stoichiometric ratio; hence, there was much lower $\mathrm{W}$ recovery. Therefore, for such high-grade $\mathrm{W}$ material, optimizing the $\mathrm{NaOH} / \mathrm{WO}_{3}$ ratio would be more beneficial for improving $\mathrm{W}$ recovery $[4,5,10,22,24]$. The control experiment in which LWTG was employed proved that LWG was a better leaching process for the historical tungsten tailings under study, as W recovery was very low (5.5\%).

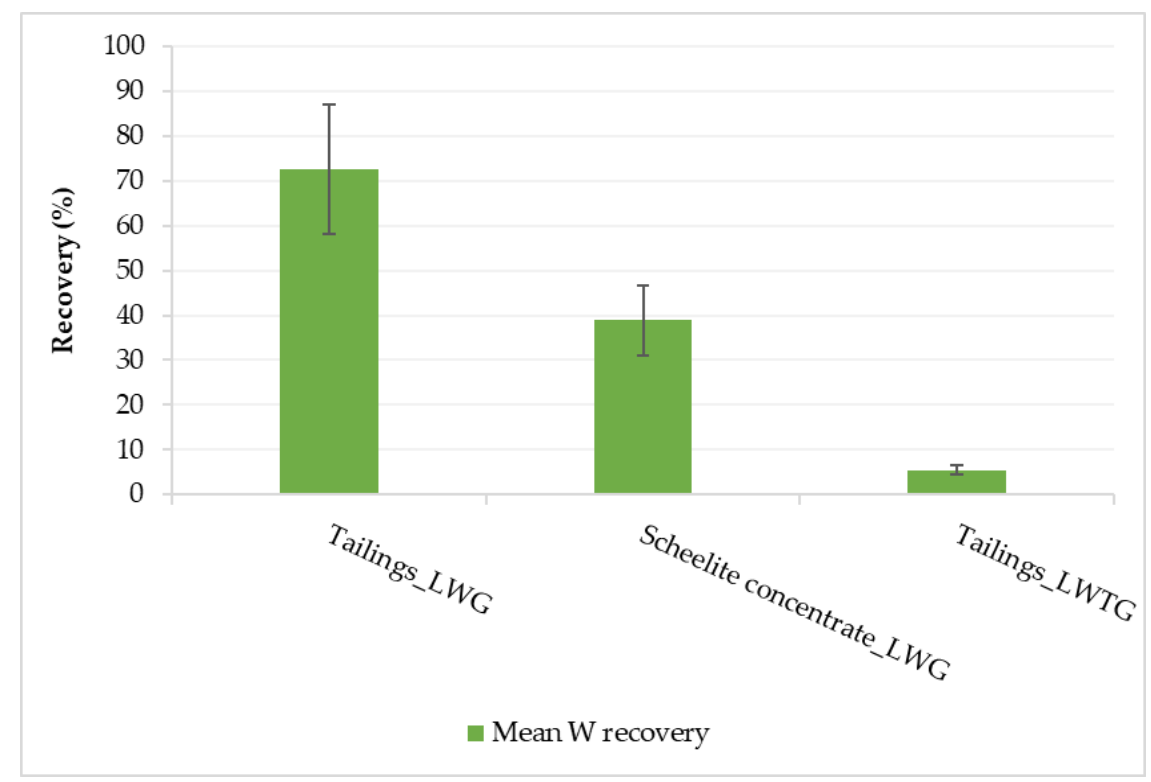

Figure 7. Mean verification results using factor settings of the best numerical optimization recommended solution.

\subsection{Effect of LWG on Particle Size and Mineralogical Composition of Residue}

In order to assess the effect of grinding on particle size, the residue (solute) from the optimized LWG of the tailings was analyzed using laser diffraction for particle size distribution. Since the feed material particle size distribution was -600 to $+75 \mu \mathrm{m}$, it was important to assess the amount of material that ended up in the fine $(<75 \mu \mathrm{m})$ fraction after grinding. From mass balancing, $55.4 \mathrm{wt} . \%$ of the ground tailings material was $<75 \mu \mathrm{m}$, 
and this fraction was analyzed using laser diffraction. Based on the three solute samples analyzed, it was observed that the average particle diameter at $80 \%$ was $5.85 \mu \mathrm{m}$ (Figure 8), meaning a substantial reduction in particle size had resulted from the grinding.

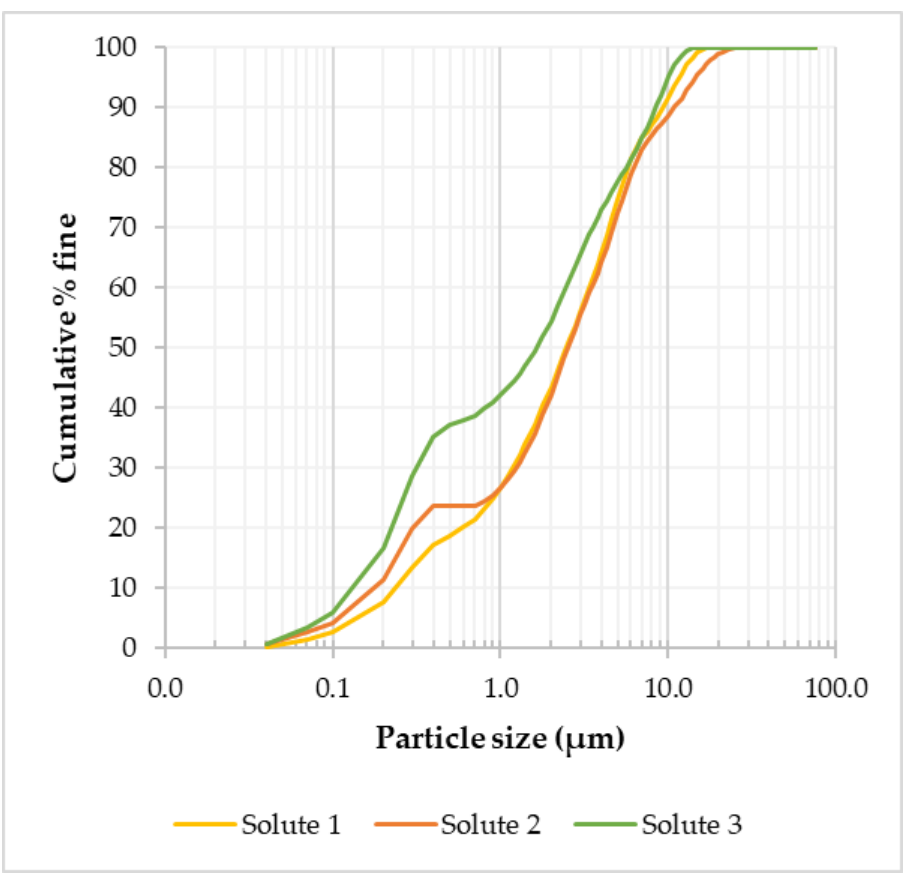

Figure 8. Particle size distribution for three LWG solute samples in the $<75 \mu \mathrm{m}$ size fraction.

For the bulk mineralogical characterization of the solute, XRD was used to determine in which phases the unleached $\mathrm{W}$ occurred. It was observed that $\mathrm{W}$ was present in both the $\mathrm{Na}_{2} \mathrm{WO}_{4}$ and $\mathrm{CaWO}_{4}$ phases (Figure 9), meaning further dissolution, achieved by increasing the duration of washing, was required to solubilize the $\mathrm{Na}_{2} \mathrm{WO}_{4}$ for $\mathrm{W}$ to be totally recovered from this phase. For the $\mathrm{W}$ in the $\mathrm{CaWO}_{4}$ phase, further analysis using scanning electron microscopy (SEM) would be required to determine if the $\mathrm{CaWO}_{4}$ remained unliberated in the coarse $(>75 \mu \mathrm{m})$ fraction, or if it resulted from the reverse reaction occurring because of the over-dilution of $\mathrm{NaOH}$ in the washing stage.

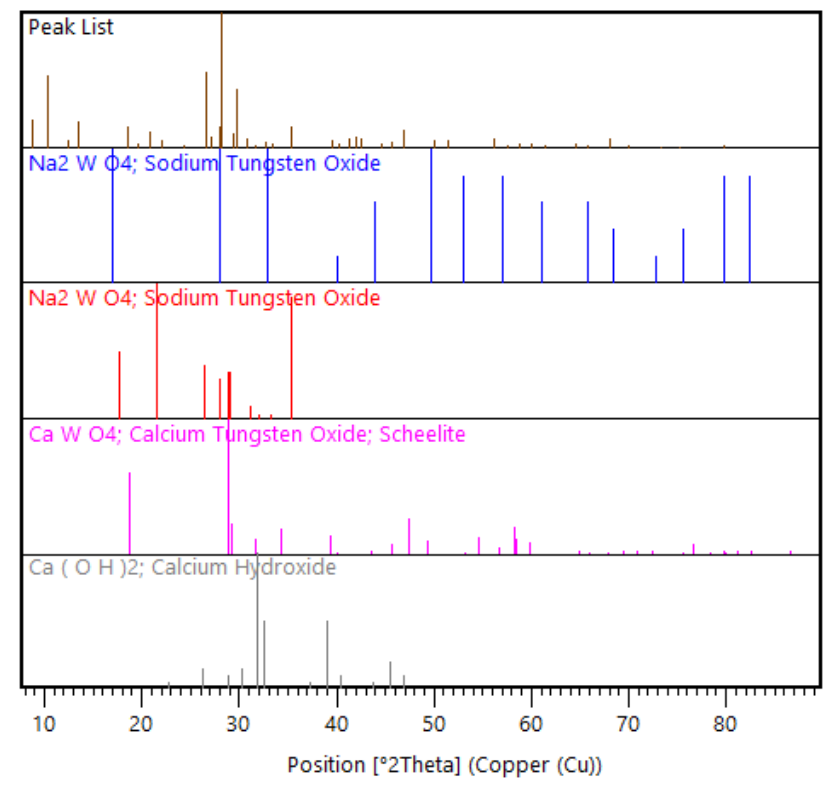

Figure 9. XRD pattern view of selected mineral phase patterns in the LWG solute. 


\section{Conclusions}

This study aimed to analyze and optimize the LWG process for W recovery from historical tungsten tailings. Leaching tests were done with a stirred media mill at different conditions. Using the regular two-level factorial design, the four factors of stirrer speed, liquid/solid ratio, temperature, and digestion time were assessed for their criticality and effects in the LWG process. The following were the findings and conclusions:

- Compared to conventional leaching, the LWG in this study was more efficient and more sustainable, especially considering that the amount of $\mathrm{NaOH}$ used was much lower, and $\mathrm{W}$ recovery was much higher at a lower leaching temperature;

- The stirrer speed and the liquid/solid ratio were the most critical factors in the maximization of $\mathrm{W}$ recovery, with an increase in the stirrer speed having a positive effect, while the liquid/solid ratio had a negative effect;

- The maximum $\mathrm{W}$ recovery $(91.2 \%)$ was attained at the highest stirrer speed (410 rpm), a low liquid/solid ratio (0.8), long digestion time (6 h), and a low leaching temperature $\left(60^{\circ} \mathrm{C}\right)$;

- With the mechanical activation of scheelite resulting from the simultaneous grinding and leaching, a low leaching temperature $\left(60^{\circ} \mathrm{C}\right)$ was attainable;

- The grinding had a substantial effect on the particle size, with $55.4 \mathrm{wt} . \%$ of the tailings feed material being ground to $<75 \mu \mathrm{m}$ from the initial particle size range -600 to $+75 \mu \mathrm{m}$, and $80 \%$ of the $<75 \mu \mathrm{m}$ size fraction having an average diameter of $5.85 \mu \mathrm{m}$;

- For low-grade $\mathrm{W}$ material, such as the historical tailings used in this study, optimizing the liquid/solid ratio is critical for maintaining substantial fluidity in the digestion mixture;

- For subsequent $\mathrm{W}$ recovery optimization, the dilution of the $\mathrm{NaOH}$ solution in the washing stage and the duration of washing would be other factors to optimize, as the $\mathrm{Na}_{2} \mathrm{WO}_{4}$ phase was observed in the solute;

- The energy conservation factor could be optimized by considering a slight reduction in the digestion time factor.

Author Contributions: Conceptualization, J.R. and J.M.; methodology, J.M.; validation, J.M.; formal analysis, J.M.; investigation, J.M.; resources, S.C.C. and J.M.; data curation, J.M.; writing-original draft preparation, J.M.; writing-review and editing, S.C.C. and J.M.; visualization, J.M.; supervision, S.C.C. and J.R. All authors have read and agreed to the published version of the manuscript.

Funding: This research was funded by Centre of Advanced Mining and Metallurgy (CAMM) at Luleå University of Technology, and The APC was funded by CAMM.

Institutional Review Board Statement: Not applicable.

Informed Consent Statement: Not applicable.

Acknowledgments: The financial contribution from the Centre of Advanced Mining and Metallurgy (CAMM) at Luleå University of Technology is gratefully acknowledged.

Conflicts of Interest: The authors declare no conflict of interest. The funders had no role in the design of the study; in the collection, analyses, or interpretation of data; in the writing of the manuscript; or in the decision to publish the results.

\section{References}

1. Blengini, G.A.; Latunussa, C.E.L.; Eynard, U.; Torres de Matos, C.; Wittmer, D.; Georgitzikis, K.; Pavel, C.; Carrara, S.; Mancini, L.; Unguru, M.; et al. European Commission, Study on the EU's list of Critical Raw Materials-Final Report (2020); European Commission: Brussels, Belgium, 2020.

2. Singh Gaur, R.P. Modern hydrometallurgical production methods for tungsten. JOM 2006, 58, 45-49. [CrossRef]

3. Leal-Ayala, D.R.; Allwood, J.M.; Petavratzi, E.; Brown, T.J.; Gunn, G. Mapping the global flow of tungsten to identify key material efficiency and supply security opportunities. Resour. Conserv. Recycl. 2015, 103, 19-28. [CrossRef]

4. Zhao, Z.; Liang, Y.; Liu, X.; Chen, A.; Li, H. Sodium hydroxide digestion of scheelite by reactive extrusion. Int. J. Refract. Met. Hard Mater. 2011, 29, 739-742. [CrossRef] 
5. Zhao, Z.; Li, J.; Wang, S.; Li, H.; Liu, M.; Sun, P.; Li, Y. Extracting tungsten from scheelite concentrate with caustic soda by autoclaving process. Hydrometallurgy 2011, 108, 152-156. [CrossRef]

6. Liu, L.; Xue, J.; Liu, K.; Zhu, J.; Wang, Z. Complex Leaching Process of Scheelite in Hydrochloric and Phosphoric Solutions. JOM 2016, 68, 2455-2462. [CrossRef]

7. Baláž, P. Mechanical activation in hydrometallurgy. Int. J. Miner. Process. 2003, 72, 341-354. [CrossRef]

8. Baláž, P.; Achimovicová, M.; Baláž, M.; Billik, P.; Zara, C.Z.; Criado, J.M.; Delogu, F.; Dutková, E.; Gaffet, E.; Gotor, F.J.; et al. Hallmarks of mechanochemistry: From nanoparticles to technology. Chem. Soc. Rev. 2013, 42, 7571-7637. [CrossRef] [PubMed]

9. Zhu, X.; Liu, X.; Zhao, Z. Leaching kinetics of scheelite with sodium phytate. Hydrometallurgy 2019, 186, 83-90. [CrossRef]

10. Zhao, Z.; Liang, Y.; Li, H. Kinetics of sodium hydroxide leaching of scheelite. Int. J. Refract. Met. Hard Mater. 2011, $29,289-292$. [CrossRef]

11. Li, T.-T.; Shen, Y.-B.; Zhao, S.-K.; Yin, Y.-Y.; Lu, R.; Gao, S.-L.; Han, C.; Wei, D.-Z. Leaching kinetics of scheelite concentrate with sodium hydroxide in the presence of phosphate. Trans. Nonferrous Met. Soc. China 2019, 29, 634-640. [CrossRef]

12. Suryanarayana, C. Mechanical alloying and milling. Prog. Mater. Sci. 2001. [CrossRef]

13. Sandström, Å. Mechanochemical Treatment in Metallurgy: An Overview. In Proceedings of the Conference in Mineral Engineering, Luleå, Sweden, 2-3 February 2016.

14. Baláž, P.; Kammel, R.; Sekula, F.; Jakabský, Š. Mechanochemical leaching: The possibility to influence the rate of metals extraction from refractory ores. In Proceedings of the Twentieth International Mineral Process Congress, Aachen, Germany, 21-26 September 1997; Volume 4, pp. 149-159.

15. Zhang, Q.; Saeki, S.; Tanaka, Y.; Kano, J.; Saito, F. A soft-solution process for recovering rare metals from metal/alloy-wastes by grinding and washing with water. J. Hazard. Mater. 2007, 139, 438-442. [CrossRef] [PubMed]

16. Veiga, M.M.; Nunes, D.; Klein, B.; Shandro, J.A.; Velasquez, P.C.; Sousa, R.N. Mill leaching: A viable substitute for mercury amalgamation in the artisanal gold mining sector? J. Clean. Prod. 2009, 17, 1373-1381. [CrossRef]

17. Gong, D.; Zhou, K.; Li, J.; Peng, C.; Chen, W. Kinetics of Roasting Reaction Between Synthetic Scheelite and Magnesium Chloride. JOM 2019, 71, 2827-2833. [CrossRef]

18. Baba, A.A.; Kayode, J.O.; Raji, M.A. Low-Energy Feasibility for Leaching an Indigenous Scheelite Ore for Industrial Applications. J. Sustain. Met. 2020, 6, 659-666. [CrossRef]

19. Ren, H.; Li, J.; Tang, Z.; Zhao, Z.; Chen, X.; Liu, X.; He, L. Sustainable and efficient extracting of tin and tungsten from wolframite-scheelite mixed ore with high tin content. J. Clean. Prod. 2020, 269, 122282. [CrossRef]

20. Li, J.; Ma, Z.; Liu, X.; Chen, X.; Zhao, Z. Sustainable and Efficient Recovery of Tungsten from Wolframite in a Sulfuric Acid and Phosphoric Acid Mixed System. ACS Sustain. Chem. Eng. 2020. [CrossRef]

21. Yunjiao, L.; Honggui, L.; Maosheng, L.; Peimei, S. Mechanical activation of alkaline leaching of scheelite concentrate. Rare Met. 1998, 17, 307-311.

22. Li, H.; Liu, M.; Sun, P.; Li, Y. Caustic decomposition of scheelite and scheelite-wolframite concentrates through mechanical activation. J. Cent. South Univ. Technol. 1995, 2, 16-20. [CrossRef]

23. Katircioglu-Bayel, D. Optimization of operating parameters on dry grinding of calcite in a stirred media mill using the BoxBehnken design. Minerals 2020, 10, 251. [CrossRef]

24. Quatrini, L.R. Tungsten Recovery from Tungsten Ore Concentrates by Caustic Digestion. U.S. Patent 4353878 A, 12 October 1982.

25. Bohlouli, A.; Afshar, M.R.; Aboutalebi, M.R.; Seyedein, S.H. Optimization of tungsten leaching from low manganese wolframite concentrate using Response Surface Methodology (RSM). Int. J. Refract. Met. Hard Mater. 2016, 61, 107-114. [CrossRef]

26. Zhao, Z.; Li, H. Thermodynamics for leaching of scheelite-pseudo-ternary-system phase diagram and its application. Met. Mater. Trans. B Process Metall. Mater. Process. Sci. 2008, 39, 519-523. [CrossRef]

27. Mulenshi, J. Geometallurgical Study of Historical Tailings from the Yxsjöberg Tungsten Mine in Sweden-Characterization and Reprocessing Options. Licentiate Thesis, Luleå University of Technology, Lulea, Sweden, 2019.

28. Mulenshi, J.; Khavari, P.; Chehreh Chelgani, S.; Rosenkranz, J. Characterization and Beneficiation Options for Tungsten Recovery from Yxsjöberg Historical Ore Tailings. Processes 2019, 7, 895. [CrossRef]

29. Mulenshi, J.; Gilbricht, S.; Chehreh Chelgani, S.; Rosenkranz, J. Systematic characterization of historical tailings for possible remediation and recovery of critical metals and minerals-The Yxsjöberg case. J. Geochem. Explor. 2021. [CrossRef]

30. Stat-Ease Regular Two-Level Factorial Designs. Available online: https://www.statease.com/docs/v12/screen-tips/intro-andbuild/factorial/regular-two-level/ (accessed on 27 December 2020).

31. Stat-Ease Interpretation of R-Squared. Available online: https://www.statease.com/docs/v12/contents/analysis/anova-output/ (accessed on 31 December 2020). 